\title{
O Estado Social e os fundamentos históricos e conceituais da política social: origem e institucionalização
}

\author{
Jonis Manhães Sales Felippe ${ }^{1}$
}

1 Doutorando em Políticas Sociais pela Universidade Estadual do Norte Fluminense Darcy Ribeiro e Mestre em Serviço Social pela Universidade do Estado do Rio de Janeiro. Assistente Social do Instituto Federal Fluminense, Brasil. E-mail: jonisfelippe@gmail.com

RESUMO: A compreensão dos contornos e tendências das políticas sociais na cena contemporânea exige, em primeiro lugar, o resgate e o aprofundamento do debate sobre o próprio conceito de política social. Considerando a natureza interdisciplinar dos estudos sobre o tema, que se traduzem em compreensões nem sempre consensuais - ainda que no mesmo campo teórico -, este artigo se propõe a discutir e contrapor algumas importantes abordagens no âmbito de produções de orientação marxista. Dessa maneira, utiliza-se a pesquisa bibliográfica como recurso metodológico para a construção de um texto com caráter revisional sobre os elementos históricos e os fundamentos teóricos desse fenômeno que ganhou corpo institucionalizado a partir do final do século XIX em alguns países centrais e início do século XX no restante do ocidente, inclusive no Brasil.

Palavras-chave: Políticas sociais, direitos sociais, Estado Social.

The Social State and the historical and conceptual foundations of Social Policy: origin and institutionalization

ABSTRACT: Understanding the trends and contours of social policies on the contemporary scene requires, first of all, the rescue and deepening of the debate about the very concept of social policy. Considering the interdisciplinary nature of the studies on the subject, which translate into not always consensual understandings - albeit in the same theoretical field - this article proposes to discuss and counter some important approaches in the field of Marxist oriented productions. In this way, bibliographical research is used as a methodological resource for the construction of a text with a revisional character about the historical elements and the theoretical foundations of this phenomenon that gained institutionalized body from the end of the 19th century in some central countries and beginning Of the 20th century in the West, including Brazil.

Keywords: Social policies, social rights, Social State.

\section{INTRODUÇÃO}

Em geral, a política social é tratada pelos autores que integram a tradição marxista (FALEIROS, 2004; NETTO, 1996; BEHRING, 2008) como um fenômeno típico da sociedade capitalista, principalmente após o reconhecimento pela burguesia e pelo Estado das desigualdades estruturais que envolvem a distribuição da riqueza produzida socialmente pelo trabalho. No entanto, essa não é uma compreensão unânime, nem mesmo entre os autores que compõem essa mesma tradição intelectual.

De acordo com Pereira (2011), no termo política social está implícita uma grande imprecisão conceitual, o que acaba por produzir sentidos vagos, associando-o com ações voluntaristas e clientelísticas e até mesmo com práticas experimentais criminosas realizadas com enfermos, judeus e grupos étnicos durante o período nazista na 
Alemanha. Há uma enorme gama de noções que varia segundo as mais diversas correntes de pensamento, o que fundamenta a necessidade de se esclarecer a perspectiva com a qual se trabalha - o marxismo.

Dentro dos próprios estudos marxistas, porém, é possível verificar também algumas discussões e divergências entre os autores sobre a sua origem histórica. Apesar disso, os intelectuais dessa corrente partilham da concepção de que a política social não pode ser entendida como uma "mera provisão ou alocação de decisões tomadas pelo Estado e aplicadas verticalmente na sociedade" (PEREIRA, 2011, p. 166), o que ignoraria os embates que envolvem as exigências e as formas de intervenção sobre o social.

Dessa maneira, os itens deste trabalho se propõem a resgatar os processos sociais e os embates entre as classes que deflagraram na construção dos modelos clássicos de proteção social pelo mundo, apresentando ao leitor um panorama temporal e conceitual para a compreensão do que é a política social e de como se deram as suas transformações na sociedade capitalista.

\section{SOBRE A ORIGEM DA POLÍTICA SOCIAL}

Alguns pesquisadores como Faleiros (2004), Behring (2008), Behring e Boschetti (2010) e Netto (2007), por exemplo, situam a política social como forma de enfrentamento às multifacetadas expressões da

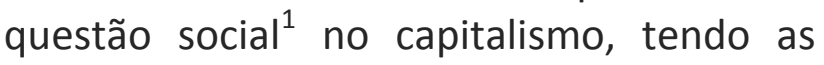

\footnotetext{
${ }^{1}$ A questão social nada mais é do que o conjunto de manifestações sociais decorrentes das contradições do processo de acumulação capitalista. Segundo lamamoto (2010 e 2012), ela tem sua gênese no caráter coletivo da produção em contraposição à apropriação privada dos resultados do trabalho, expressando-se por meio dos fenômenos do pauperismo, da exclusão, da desigualdade, do desemprego, etc.
}

primeiras legislações fabris de regulação do trabalho um papel de percussoras nas funções que caberão ao Estado em relação aos conflitos entre as classes operária e burguesa, bem como na conquista dos direitos sociais a partir dos séculos XIX e, principalmente, XX.

Assim, até a primeira metade do século XIX, teria vigorado a repressão como a principal forma de resposta do Estado às sequelas derivadas do conflito entre as classes. Ao final desse mesmo século e no decorrer do século $X X$, com o desdobramento das lutas dos trabalhadores organizados politicamente, passaram a ser incorporados outros tipos de resposta vinculados à criação de legislações e à realização de investimentos em políticas sociais públicas. Segundo Behring e Boschetti (2010), houve uma alteração na perspectiva do Estado liberal, que passou a absorver orientações de cunho social-democrata, reconhecendo e assegurando certas reivindicações dos trabalhadores para não ver os próprios fundamentos do capitalismo colocados em xeque.

Também vinculada aos estudos de orientação marxista, Pereira (2011) discorda dessa concepção e identifica um equívoco conceitual e histórico nessa perspectiva, uma vez que seriam igualados dois fenômenos distintos: a política social e o Welfare State. Para a autora, o que se construiu a partir do século XIX em boa parte dos países centrais foi um tipo específico e historicamente determinado de Estado, denominado de Bemestar social, responsável por construir um modelo de cidadania e de regulação socioeconômica distinto das formas anteriores fundadas no paternalismo.

Esse modelo de Estado teria surgido com o crescimento da consciência do proletariado enquanto classe explorada e dos confli- 
tos decorrentes da afirmação da burguesia como classe dominante, momento em que a questão social ganhou visibilidade e passou a exigir formas mais efetivas de regulação das forças do mercado e das tensões sociais. Dois grandes elementos, ressalta Pereira (2011), teriam contribuído para esse processo: a Revolução Industrial no século XVIII e a eclosão da democracia de massas crescimento das mobilizações sociais.

A revolução das formas, técnicas e instrumentos possibilitou o desenvolvimento de uma capacidade nunca vista de produção de bens materiais, capaz de libertar os homens dos tormentos da escassez e da pobreza que se arrastavam desde o final da Idade Média. Apesar disso, o que se experimentou foi um processo de aprofundamento das desigualdades, revelando a natureza exploradora e perversa do modo de produção capitalista.

No que se refere à democracia de massas, a autora destaca a transformação do Estado absolutista em Estado social de direitos, com especial atenção para a progressiva ampliação do alcance dos direitos políticos aos trabalhadores (século XIX). Esse fator permitiu o desenvolvimento das organizações de massa, dos partidos e sindicatos, que resultaram numa maior participação e ingerência das parcelas exploradas da população nas decisões e ações do Estado em relação às sequelas da questão social.

Diante dessa exposição, Pereira (2011, p. 176-177) ratifica que o século XIX foi central para a constituição do Welfare State, um Estado que, embora apresente grandes variações em relação à abrangência e à forma entre os diversos países centrais, pode ser caracterizado como um modelo "capitalista regulador e provedor de benefícios e servi- ços sociais" consolidado no século XX. Seus objetivos e políticas estão centrados na noção de cidadania e se inspiraram nos seguintes elementos: "extensão dos direitos sociais, oferta universal de serviços sociais, preocupação com pleno emprego e institucionalização da assistência social".

Dessa maneira, apesar de a política social ter experimentado um período de grande expansão e até modificação de seus pressupostos durante a fase do Welfare State, ela não se confunde com ele na visão de Pereira (2011). Segundo a pesquisadora, essa falta de distinção entre os dois fenômenos muitas vezes é responsável por se transferirem para a política social as frustrações pela não concretização do bemestar associado ao Estado capitalista após a Segunda Guerra Mundial. Também com base nessa mesma premissa, produzem-se prognósticos de crise e até mesmo de fim das políticas sociais, o que, segundo a autora, não está em vias de se concretizar em nenhum país em que elas foram construídas. O que entrou em crise e vem sendo desconstruído em muitos países, assim mesmo com resistências, é o Welfare State e não a política social. Esta, na realidade, vem sofrendo transformações e reconfigurações, como ocorreu durante toda a sua trajetória.

Por conseguinte, a política social seria um conceito mais amplo e sujeito a variações de acordo com os regimes políticos que a sustentam, não restrito ao modo de produção capitalista, além de nem sempre ter sido vinculada às concepções contemporâneas de direito social. Nessa linha de raciocínio, Pereira (2011, p. 28) classifica essa política como componente ou produto "da velha e conflituosa relação entre Estado e sociedade, no marco das formações soci- 
ais de classe" [ou castas], aí incluídas as experiências escravistas, feudais e capitalistas.

Para demonstrar historicamente seus argumentos, Pereira (2011) resgata diversas formas, embora pontuais e ainda socialmente restritas, de atendimento às necessidades sociais. Destaca-se que a professora não aborda as ações de caridade realizadas por agentes individuais, mas apenas os exemplos clássicos de intervenção do Estado (ainda que em construção nos moldes modernos) voltados para o planejamento e a execução de ações direcionados à amenização das mazelas sociais. Tais iniciativas, denominadas genericamente de Leis dos pobres $^{2}$, representariam formas de política social que se basearam em objetivos relacionados ao controle social, à legitimação do governante e até mesmo à doutrinação.

Destaca-se que essas legislações e práticas, iniciadas no século XIV, partiam da constatação de que a caridade cristã não era capaz de conter os efeitos das desordens e mazelas geradas pela transição do feudalismo para o capitalismo, além do crescimento exponencial da miséria e da "vagabundagem" decorrentes das epidemias e pragas. Veja que essa posição é bem diferente da adotada por Behring e Boschetti $(2010$, p. 63) quando afirmam que as "primeiras iniciativas de políticas sociais podem ser entendidas na relação de continuidade entre Estado liberal e Estado social", portanto, a partir do século XIX. Também se distingue das formulações de Netto

\footnotetext{
${ }^{2}$ Conjunto de legislações sociais criadas no final da Idade Média na Inglaterra e reeditadas até o século XIX. Tinha como objetivo central o controle dos fenômenos da pobreza e da "vagabundagem", prevendo ações que abarcavam a regulamentação da perambulação, a oferta de abrigo para os incapazes, o cerceamento da liberdade de ir e vir, o trabalho compulsório (Workhouses). Para mais informações, ver Pereira (2011).
}

(1996, p. 26), pois o autor reitera que só é possível pensar em política social pública nessa etapa do capitalismo, quando finalmente passam a adquirir um caráter sistemático, contínuo e estratégico sobre as expressões da questão social.

Ademais, em que pese às divergências histórico-conceituais, há um ponto de concordância entre as produções acadêmicas aqui abordadas. Tanto Pereira (2011) quanto Faleiros (2004), Behring e Boschetti (2010) e Netto (1996) são concordes em apontar que é no último terço do século XIX e, principalmente, com a consolidação do Estado de Bem-Estar social após a Segunda Guerra Mundial, que a política social ganha densidade institucional e dimensão cívica, passando a vincular-se à noção de direito social e, por conseguinte, à ideia de cidadania.

Sobre esse assunto, uma obra clássica de bastante relevância é a construída por Marshall (1967) - Cidadania e classe social. Esse sociólogo, muito voltado para a análise da experiência britânica, propõe-se a analisar o desenvolvimento da cidadania na modernidade, entendendo-a como um status que é concebido aos membros integrais de uma comunidade, ou seja, àqueles que possuem as condições plenas de participação.

A sua concretização, porém, dependeria da existência de direitos e deveres - obrigações do Estado para com os indivíduos e dos indivíduos para com o Estado. Chama atenção o fato de que Marshall (1967) identificava certo nível de aceitabilidade em relação à desigualdade no capitalismo, desde que fosse garantido pelo Estado um certo padrão de vida que possibilitasse a participação política dos indivíduos. A cidadania só poderia ser pensada dentro das relações capitalistas, pois, no feudalismo, não havia 
a possibilidade de reconhecimento de qualquer nível de igualdade entre as classes ou castas.

Nesse contexto, os direitos no capitalismo seriam indicadores de cidadania e poderiam ser compreendidos numa trajetória mais ou menos progressiva que partia das conquistas civis no século XVIII, passando pelas garantias políticas no século XIX, até a consolidação dos direitos sociais no século XX. Assim, Marshall (1967) descreve um conjunto de acontecimentos históricos, como o fim da censura à imprensa, a possibilidade de se escolher com quem trabalhar e a garantia da possibilidade de locomoverse livremente como as primeiras grandes conquistas em direção à aquisição da cidadania.

Todas essas garantias iniciais, consolidadas com a Revolução Francesa de 1789, possibilitaram a adição gradativa de novos direitos (civis) em relação ao modo de produção anterior, baseado na servidão. Elas teriam aberto as possibilidades para a incorporação dos direitos políticos (já existentes para a aristocracia) aos novos grupos e classes sociais, inicialmente burgueses homens, depois trabalhadores homens e, em última escala, mulheres. Os direitos sociais teriam sido o último estágio de conquista do status de cidadania e objetivavam a redução das desigualdades entre as classes, garantindo um nível básico de regulação do trabalho e de satisfação de necessidades sociais. Marshall (1967) destaca os diversos conflitos que se construíram entre os direitos políticos e os sociais, mas ressalta o entrelaçamento entre ambos.

Apesar das contribuições, muitas críticas foram dirigidas à obra de Marshall, apontando a atenção incipiente dada pelo autor ao papel determinante das lutas sociais na conquista dos direitos de cidadania. Além disso, mesmo para um caso bastante específico que é o britânico, a ideia de que houve uma escalada gradual de aquisição dos direitos durante o tempo indica uma possível leitura evolucionista da história, bastante preocupante quando utilizada para a interpretação da situação de países que experimentaram a ampliação de direitos sociais em períodos de cerceamento dos direitos políticos ou civis, por exemplo. É nessa linha que Saes (2003) aponta a existência de um déficit teórico e não apenas histórico nas análises do intelectual inglês.

Independentemente das críticas, é inegável que a contribuição de Marshall (1967), mesmo com seus limites, trouxe importantes referências para se interpretar a estrutura adquirida pelas políticas sociais no final do século XIX e no decorrer do XX. Como se viu, é nesse período que as intervenções sobre o social vinculam-se à noção de cidadania, ainda que nos moldes capitalistas. O próprio sociólogo britânico afirmava que não seria suficiente a letra da lei para a garantia da cidadania, dada a necessidade de instituições que assegurem a sua efetivação.

\section{A INSTITUCIONALIZAÇÃO DA POLÍTICA SOCIAL NO SÉCULO XX}

No que diz respeito aos direitos sociais e a criação de instituições públicas para assegurá-los, Behring e Boschetti (2010), Netto (1996), Faleiros (2004) e Pereira (2011) são concordes ao apontar a experiência alemã de previdência como iniciativa pioneira na formulação do sistema de proteção que posteriormente se concretizou como Estado de Bem-Estar, Estado social ou Estado providência, segundo as diferentes concepções 
teóricas. Tais autores identificam no governo de Oto Von Bismarck o início de um modelo de segurança social inovador em relação a todas as experiências anteriores de intervenção social, públicas ou privadas.

Inaugurada no ano de 1880, a legislação alemã previa a criação de um seguro social público e obrigatório voltado para a reposição da renda de trabalhadores e de suas famílias em situações como morte, acidente de trabalho, doença, velhice, desemprego. Portanto, há finalmente um reconhecimento efetivo por parte do Estado de que os efeitos da questão social, inclusive a pobreza, atingiam ou poderiam atingir não apenas os indigentes, mas o proletariado em geral.

Mesmo assim, a iniciativa alemã não deixou de ser um avanço significativo na história da política social secularmente caracterizada como um socorro paliativo aos pobres, mesmo que se restringisse a um grupo estrategicamente específico - o trabalhador - e fosse usado como antídoto às ideias socialdemocratas que, na Alemanha da época, rondavam a classe operária. Por isso, é válido pensar que a legitimação do seguro social pelo Estado significou a inauguração de uma prática, que se faz presente até hoje, de tratar a política social como direito requerido pela sociedade e encampado pelos poderes públicos (PEREIRA, 2011, p. 60 e 61).

Como toda política social, esse modelo de seguro, hoje conhecido como uma das possibilidades de previdência, estava carregado de contradições, pois, ao mesmo tempo em que representava a conquista de alguma forma de proteção ao trabalho em relação às flutuações e incertezas da sociedade de mercado, expressava uma importante estratégia econômica do Estado capitalista. É o que destaca Netto (1996) ao as- severar que tal modelo foi utilizado para evitar a tendência do subconsumo e da queda da demanda no mercado, além de ter concentrado massas de recursos nas mãos do Estado - inclusive utilizando tais fundos para financiar investimentos de interesse do capital.

Seguindo essa linha, Behring e Boschetti (2010) descrevem também o intuito de controle sobre o proletariado alemão, desarticulando as caixas de poupança e previdência criadas por segmentos da classe trabaIhadora que serviam, entre outras coisas, para financiar o movimento operário. A proteção social, no entanto, deixava ineditamente de ser barreira para a participação nas decisões, coexistindo enquanto direito ao lado das conquistas civis e políticas.

Esse modelo se espalhou rapidamente pela Europa e pelos demais continentes, fazendo com que, no início do século XX, mais de 70 países pelo mundo tivessem alguma forma de seguro social (MARSHALL, 1967). Nota-se que esse modelo de proteção era baseado na contribuição direta do trabalhador e do próprio empregador, em muitos casos. Segundo Faleiros (2004), a consagração desse modelo, associado com a previsão de direitos trabalhistas, deu-se com o tratado de Versalhes no final da Primeira Guerra mundial (1914-1918).

Sobre esse assunto, Behring e Boschetti (2010) ressaltam o período entre a primeira e a Segunda Guerra Mundial como central para a multiplicação das políticas sociais pelo mundo. Segundo as pesquisadoras, uma série de fatores contribuiu para que as concessões do capital em relação às demandas sociais das classes subalternas fossem efetivadas. Em primeiro lugar, a expansão do movimento socialista mundialmente, com destaque para a revolução russa em 
1917, configurou uma alternativa real ao modo de produção capitalista.

Um segundo elemento refere-se à crescente monopolização e concentração do capital, processo que ruiu o discurso liberal de livre mercado como forma mais bem acabada de regulação social. Pelo contrário, a concorrência entre capitais cada vez maiores, fundidos com o capital bancário, promoveu um nível extremamente predatório de competição, deflagrando em duas grandes guerras mundiais e no questionamento do potencial civilizatório da sociedade de mercado. Por último, a grande depressão de 1929 produziu uma verdadeira devastação das economias mundiais, gerando desemprego em massa e reduzindo o comércio mundial a um terço do que era antes (BEHRING; BOSCHETTI, 2010).

Todo esse processo, logo nas primeiras décadas do século $X X$, exigiu mudanças profundas no regime de acumulação e nos modos de regulamentação social e política. De acordo com Harvey (2009), para não ver o sistema colocado em xeque, o capital se viu obrigado a negociar pelo menos dois pontos básicos do liberalismo clássico: a anarquia dos mercados e o controle sobre o emprego da força de trabalho.

Sobre o primeiro aspecto, procedeu-se ao reconhecimento da ineficiência da mão invisível do mercado como reguladora autônoma das relações econômicas, o que resultou no progressivo incremento da participação do Estado na busca pelo "equilíbrio econômico". Seguindo as propostas de John Keynes ${ }^{3}-1936$, muitos países realiza-

${ }^{3}$ Economista britânico crítico das concepções neoclássicas de livre regulação pelo mercado. Inaugurou uma nova perspectiva de macroeconomia, sujos fundamentos centravam-se na defesa da intervenção estatal, com medidas fiscais e monetárias, para controlar os ciclos ram mudanças na política monetária e cambial, ampliaram a execução pública de atividades de investimento não exploradas pela iniciativa privada, aumentaram a tributação para formar fundos de reserva em períodos de crise e incrementaram o subsídio financeiro ao capital.

Já em relação ao segundo ponto, experimentou-se um alargamento substancial das formas e mecanismos de regulação das relações entre capital e trabalho, garantindo um alcance mais abrangente das políticas sociais e uma maior proteção ao trabaIho. Consequentemente, foram acrescidas e complexificadas também as formas de intervenção e controle sobre a vida do trabaIhador, tendo como objetivo principal adaptá-lo, inclusive em termos comportamentais, às novas requisições promovidas pelo novo regime de produção implantado.

Esse modelo de acumulação, cujos princípios fundamentais foram formulados a partir de 1914, baseava-se na intensificação da divisão do trabalho por meio da decomposição do processo de produção e da adoção de uma posição fixa do trabalhador na linha produtiva. Outra modificação consolidada por essa nova organização produtiva foi a intensificação da separação entre gerência, concepção, controle e execução das tarefas, reduzindo ainda mais a conexão entre o trabalho e os conhecimentos necessários ao processo produtivo. Contudo, Harvey (2009) ressalta que a grande inovação promovida por esse regime, que ficou conhecido como fordismo, foi a associação entre produção em série e consumo de massa.

Tratava-se, nas palavras do mesmo geó-

econômicos de crescimento e recessão (BEHRING; BOSCHETTI, 2010). 
grafo, da criação de uma nova forma de se viver, de uma nova sociabilidade e de um novo trabalhador. A ideia era aumentar o tempo livre, garantir uma expansão do emprego e elevar o poder de compra dos salários, permitindo que o próprio trabalhador consumisse as novas mercadorias. No entanto, as propostas de Henry Ford não se concretizaram num primeiro momento, pois havia uma forte resistência dos sindicatos, além de crises constantes. Apenas a partir de 1945, após a Segunda Guerra Mundial e com a adoção das propostas keynesianas em relação ao Estado, é que o modelo fordista se consolidou no âmbito da produção.

É nessa direção que se identifica no Estado de Bem-Estar social pós-guerra, período que, como visto, procedeu-se a uma ampliação efetiva das políticas sociais, vinculando-as à noção de direito social, a realização de um grande pacto social entre capital, trabalho e Estado. O capital, pelas constantes crises e pela ameaça das propostas do socialismo real, viu-se obrigado a acatar algumas pautas históricas dos trabalhadores; o operariado, em troca de tais conquistas e pressionado pela necessidade de aumento da produção após a devastação do pós-guerra, permitiu uma maior racionalização da produção e o aumento do controle sobre o seu cotidiano, abrindo mão dos ideais revolucionários; o Estado, alimentado pelas disputas entre as classes fundamentais, assumiu um papel intervencionista e estratégico para a saída da crise e a garantia da certo nível de estabilidade - mantida pelo menos até 1973 em diversos países centrais.

Tal intervenção estatal para fugir da armadiIha recessiva provocada pelas decisões dos agentes econômicos individuais, com destaque para o empresariado, tinha em perspectiva um programa fundado em dois pilares: pleno emprego e maior igualdade social, o que poderia ser alcançado por duas vias a partir da ação estatal: 1. Gerar emprego dos fatores de produção via produção de serviços públicos, além da produção privada; 2 . Aumentar a renda e promover maior igualdade, por meio da instituição de serviços públicos, dentre eles as políticas sociais (BEHRING; BOSCHETTI, 2010, p. 86).

Alguns críticos mais conservadores desse período destacam que esse Estado social ou "providência" teria se construído como efeito do reforço do vínculo cívico provocado pelas guerras, promotor de uma reformulação do contrato social pelo risco de se voltar à barbárie. Assim, a opacidade gerada pelos riscos a que todos estariam sujeitos em fases de guerra teria sustentado a construção de direitos sociais e regimes de proteção fundados na noção de igualdade (ROSANVALLON, 1998). Já para Robert Castel (1998), operacionalizou-se a generalização do assalariamento e uma homogeneização dos indivíduos enquanto detentores de direitos no Estado, colocando sobre as políticas sociais a tarefa de manter a coesão social.

A quebra desses pressupostos fundados no assalariamento fez surgir a tese de que haveria uma nova questão social nos últimos quarenta anos. Netto (2013) critica essas concepções e aponta a permanência, durante o Welfare State, da mesma contradição central entre as classes, embora o longo período expansivo tenha feito parecer que a questão social havia sido superada. Não há mudança no princípio de que a produção organiza-se em função do lucro, fato que não anula as mudanças promovidas no regime de acumulação e no modo de 
regulamentação social e política do trabaIho durante a chamada Era de Ouro do capitalismo (HARVEY, 2009).

De fato, também pode-se falar de uma "Era de Ouro" na política social, pois foi esse período histórico específico que possibilitou uma alteração efetiva dos padrões de proteção social, incorporando, inclusive, serviços com caráter universal em alguns países. Sobre esse assunto, destaca-se o Relatório Beveridge sobre o Seguro Social e Serviços Afins, elaborado em 1942 por um comitê britânico coordenado por Willian Beveridge e implantado na Inglaterra após 1945. Avançando em relação às propostas contributivas de seguro já bastante ramificadas pelo mundo, esse novo modelo de proteção articulou serviços com caráter universal e distributivo no âmbito da assistência social e da saúde, o que subsidiou a formulação de sistemas de seguridade social em muitos países.

A despeito de tais constatações, a política social do Welfare State não pode ser compreendida como um fenômeno uniforme entre as diferentes nações. Pereira (2011) reitera a existência de variações até bastante significativas, as quais vão desde experiências residuais e relutantes como nos Estados Unidos da América até o modelo sueco, considerado extremamente avançado e institucionalizado. No meio desses opostos, ressalta a pesquisadora, há uma variedade de modelos com graus significativamente diferenciados de atendimento às necessidades sociais.

No caso brasileiro, por exemplo, muitas interpretações acadêmicas apontam para a inexistência de uma política de bem-estar social, mesmo após 1988, sobretudo porque utilizam a experiência europeia como modelo. Nessa linha, Draibe (1989) e Loba- to (2016) reconhecem uma tendência de se abordarem as políticas sociais brasileiras de forma fragmentada e não como sistema, dado o histórico de pouca eficácia e efetividade dos serviços, a multiplicidade de fundos, a opacidade na administração e o desenvolvimento dos direitos sociais como forma de legitimar regimes e projetos de poder.

Contudo, Draibe (1989) também contesta a concepção homogênea que muitas vezes se atribui ao conceito de Welfare State ao resgatar trajetória de padrões mais progressistas (estatizados e universais) e conservadores (seletistas e privatizados) de atendimento às necessidades sociais. Mesmo com as variações, é possível descrever elementos ou pressupostos comuns nas diferentes definições de proteção social dentro do Welfare State, são eles: 1 - participação do Estado como referência na organização e implementação das políticas sociais; 2 - substituição da renda quando ela é perdida temporária ou permanentemente, dados os riscos da economia, a maternidade, a doença e a velhice; 3 - oferta de serviços sociais básicos gratuitamente em áreas centrais como saúde, assistência social e educação (com variações significativas nos tipos, na abrangência e no público a ser atendido).

\section{CRISE DO WELFARE STATE E MUDANÇAS NAS POLÍTICAS SOCIAIS}

Autores como Harvey (2009) e Botelho (2008) apontam que o modelo de proteção construído no Welfare State em muitos países só se sustentou historicamente em razão da longa onda de expansão econômica do capitalismo entre 1945 e a metade dos anos de 1970. Esse ciclo de crescimento 
começa a dar sinais de esgotamento já no final da década de 1960, com a industrialização dos países periféricos e a recuperação do Japão e de outros países devastados pela guerra.

Tais eventos fizeram aumentar o nível de competição internacional, demonstrando a volatilidade e a incapacidade de se anularem as contradições e as tendências de crises inerentes a esse modo de produção. De acordo com dados apresentados por Netto e Braz (2010), todas as principais economias de mercado (entre elas Alemanha, Estados Unidos, Grã-Bretanha, Itália e até mesmo o Japão) apresentaram quedas nas taxas de lucro entre $2 \%$ e $6 \%$ no período de 1968 a 1973. Para Harvey (2009), a rigidez do fordismo (em termos de contrato de trabalho, de compromissos estatais e do fluxo de produção) dependia de um mercado estável, algo já em vias de se desfazer no final dos anos 60 do século passado.

Havia um esgotamento das possibilidades de consumo e um aumento do capital excedente não utilizado, que se somaram ao crescimento da inflação pela emissão de moeda, em especial com a decisão dos Estados Unidos de desvincular o dólar do ouro, e a deliberação da Organização dos Países Exportadores de Petróleo ${ }^{4}$ de aumentar o preço do petróleo em 1973. Netto e Braz (2010) também enfatizam os fatores sociopolíticos que pesaram nesse processo, com destaque para o poder de reivindicação do movimento sindical e o surgimento de movimentos sociais (feminista, estudantil, LGBT, etc.) questionadores da cultura e dos componentes comportamentais implanta-

\footnotetext{
${ }^{4}$ Organização criada em 1960 com o objetivo de centralizar a coordenação da política energética de petróleo dos países associados, restringindo a oferta e controlando os preços no mercado.
}

dos no capitalismo do pós-guerra.

A crise econômica caracterizou-se por um processo de recessão generalizada nos países centrais a partir da segunda metade da década de 1970, fazendo surgir um conjunto de propostas de flexibilização das relações de trabalho, de produção e de consumo, o qual foi apresentado como alternativa para a recuperação das taxas de lucro do capital, algo que até hoje não se concretizou na comparação com o ritmo experimentado durante a "Era de Ouro". Não serão tecidas considerações detalhadas sobre essas mudanças, responsáveis pela inauguração de uma nova etapa nomeada por Harvey de "acumulação flexível", pois isso demandaria um trabalho específico.

Interessa aqui registrar somente que essa nova conjuntura colocou em xeque, conforme colocações de Montaño (2003), a proposta do Welfare State enquanto um modelo de intervenção social, regido por um tipo de relação entre Estado e sociedade que foi capaz de ampliar a extensão dos direitos sociais e, consequentemente, das políticas sociais responsáveis pela sua concretização. Com o advento de um novo regime de acumulação baseado na flexibilização da economia e da vida, (res)surgem propostas de modificação do papel do Estado, impactando diretamente a configuração das políticas sociais.

Também se registra nesse mesmo período uma mudança cultural bastante importante. No lugar da concepção de solidariedade social que sustentou o pós-guerra e o Estado de Bem-estar Social, colocam-se o individualismo e o empreendedorismo como grandes virtudes a serem incentivadas. O acordo construído pelas classes durante os anos de crescimento é desfeito, dando lugar ao ressurgimento dos ideais do libera- 
lismo clássico ainda mais radicalizados, dentre os quais se destaca a redução das funções sociais do Estado.

Nas palavras de Behring (2008) e de Montaño (2003 e 2014), há uma responsabilização dos trabalhadores pela crise fiscal do Estado, dado o crescimento das reivindicações em torno da ampliação da proteção social. As políticas sociais universais e abrangentes são vistas como paternalistas, geradoras de desequilíbrio, de alto custo e incentivadoras da preguiça e do ócio. Além disso, há um crescimento considerável do setor de serviços e a invasão do capital em áreas anteriormente não dominadas essencialmente pela lógica de mercado, como a saúde, a educação e a previdência.

Para permear os setores citados acima é preciso diminuir a ingerência do Estado sobre eles, transportando para o mercado a possibilidade de acesso às políticas sociais anteriormente públicas. Nesse contexto, vão perdendo progressivamente a sua vinculação com a noção de direito social, transformando-se em direito de consumo. Ao poder público passa a caber a responsabilidade apenas em relação aos sujeitos que não podem adquirir nas relações de troca tais serviços, assim mesmo reduzindo-os ao mínimo possível - o que essa noção de mínimo abarca varia, obviamente, de país para país, a depender das conquistas históricas e do poder de resistência das classes subalternas.

Nesse contexto, uma estratégia que vem sendo apontada por Montaño (2014) para gerar aceitação da população e encobrir essa redefinição dos papéis do Estado na era da acumulação flexível é o crescimento do terceiro setor. Trata-se, na visão do autor, de uma miscelânea de indivíduos, empresas e organizações não governamentais que assumem muitas das funções sociais anteriormente sob responsabilidade direta do poder público. Cria-se uma imagem de compensação das perdas dos direitos sociais pelo incentivo (inclusive fiscal, aumentando o lucro das empresas) às atividades assumidas pelo terceiro setor.

Dizíamos que a função ideológica das parcerias era não a de compensar, mas a de encobrir e gerar aceitação. Isto é, o Estado, que comandado pelo capital se reestrutura, desvencilha-se progressivamente da atividade social (e alivia o capital na coresponsabilidade do seu sustento), recortando financiamentos, focalizando, descentralizando, diminuindo a abrangência, ou diretamente eliminando políticas sociais e assistenciais (MONTAÑO, 2003, p. 226).

Como se vê, há uma tentativa de se responsabilizar o Estado Social e, consequentemente, as políticas sociais, colocando-os como iniciativas ineficientes, falidas e paternalistas, propondo como alternativa a focalização das ações em públicos cada vez mais específicos - os pobres e miseráveis (LAURELL, 1995; FREIRE, 2013; FELIPPE, 2014). Também se destacam as tentativas de formulação das parcerias públicoprivadas, materializadas, muitas das vezes, na transferência direta das responsabilidades estatais para a sociedade civil ou terceiro setor.

\section{CONSIDERAÇÕES FINAIS}

A política social no modo de produção capitalista deve ser compreendida como uma forma de intervenção do Estado que possibilita o acesso da população, ou de parte dela, a um conjunto de bens e serviços pertencentes à riqueza material e espi- 
ritual produzida pelo trabalho (aos direitos sociais). O nível, a abrangência e o volume daquilo que se acessa depende diretamente de fatores históricos, econômicos e políticos, destacadamente os que dizem respeito ao embate entre as classes sociais. Nesse sentido, a existência da política social só se justifica nos moldes atuais pela natureza exploradora e pela distribuição desigual dos frutos do trabalho, sem os quais o caráter distributivo, redistributivo ou mesmo compensatório dessa modalidade de intervenção estatal não teria razão de existir.

Em períodos de maior ameaça a ordem vigente por parte da mobilização das classes subalternas é possível se visualizar, geralmente em articulação com ações de repressão, a abertura de janelas históricas para a ampliação da oferta de políticas sociais. Épocas de crescimento econômico, em que as taxas de lucro se alargam e a pobreza relativa tende a crescer, alguns direitos sociais também podem ser conquistados pela ameaça de interrupção dos ciclos de expansão.

No entanto, o que vem sendo experimentado desde a década de 1970 em escala mundial é uma sucessão de crises na maior parte das economias globais, com períodos curtos de crescimento interrompidos por depressões em 1971, 1973, 1979, 1980, 1987, 1994, 1997, 2002, 2009 e 2015. Nesse contexto, também em escala mundial, tem se construído uma ideologia de flexibilização dos padrões de produção, de consumo, de mobilização política e de proteção social. Essa nova leitura de realidade caracteriza como obsoletos os modelos de política social adquiridos entre o final do século XIX e o início do século XX, consolidados na grande fase de expansão denominada de Era de Ouro do capitalismo (1945-1970).
No Brasil, essa ideologia ganhou corpo no decorrer da década de 1990, poucos anos após a promulgação da Constituição Federal de 1998, cujas definições acerca das políticas e direitos sociais tinham inspirações naquilo que se consolidou como padrão de proteção social nos países centrais durante o Welfare State. Assim, no lugar de políticas sociais relativamente abrangentes, em alguns casos com caráter universal, começaram a ser tomadas medidas no sentido de se adequar o seu enfoque e os seus objetivos, direcionando-as para públicos cada vez mais selecionados. Contudo, essas novas configurações, inclusive em relação ao que vem acontecendo no caso brasileiro, só podem ser pensadas criticamente se se compreender os fundamentos históricos e teóricos da política social.

\section{REFERÊNCIAS}

BEHRING, E. Brasil em contra-reforma: desestruturação do Estado e perda de direitos. São Paulo: Cortez, 2008.

BEHRING, E.; BOSCHETTI, I. Política social: fundamentos e história. São Paulo: Cortez, 2010.

BOTELHO, A. Do fordismo à produção flexível: o espaço da indústria num contexto de mudanças das estratégias de acumulação do capital. São Paulo: Annablume, 2008.

CASTEL, R. As metamorfoses da questão social: uma crônica do salário. Petrópolis: Vozes, 1998.

DRAIBE, S. M. O WelfareState no Brasil: características e perspectivas In: Ciências Sociais Hoje. São Paulo: ANPOCS/Vértice, p. 13-61, 1989.

FALEIROS, V. P. O que é política social? (Coleção primeiros passos). São Paulo: Brasiliense, 2004. 
FELIPPE, J. Os novos rumos das políticas sociais: aproximações críticas. Interfaces científicas - Humanas e Sociais, Aracajú, v. 2, n. 3, p. 47-54, 2014.

FREIRE, S. Políticas sociais para a pobreza: a pobreza das políticas. In: SOUZA, G. (Org.) 0 Social em perspectiva: Políticas, trabalho, Serviço Social. Maceió, EDUFAL, p. 47-61, 2013.

HARVEY, D. Condição pós-moderna. São Paulo: Loyola, 2009.

IAMAMOTO, M. O Serviço Social na contemporaneidade: trabalho e formação profissional. São Paulo: Cortez, 2010.

. Serviço Social em tempo de capital

fetiche: capital financeiro, trabalho e questão social. São Paulo: Cortez, 2012.

LAURELL, A. Avançando em direção ao passado: a política social no neoliberalismo. In: LAURELL, A. (Org.). Estado e políticas sociais no neoliberalismo. São Paulo: Cortez, 1995.

LOBATO, L. Políticas sociais e modelos de bem-estar social: fragilidades do caso brasileiro. Saúde Debate. Rio de Janeiro, v. 40, número especial, p. 87-97, 2016.

MARSHALL, T. H. Cidadania, classe social e status. Rio de Janeiro: Zahar, 1967.

MONTAÑO, C. Terceiro setor e questão social: crítica ao padrão emergente de intervenção social. São Paulo: Cortez, 2003.

. O canto da sereia: crítica à ideologia e aos projetos do terceiro setor. São Paulo: Cortez, 2014.

NETTO, J. P. Capitalismo monopolista e serviço social. São Paulo: Cortez, 1996.

. Desigualdade, pobreza e Serviço Social. Em Pauta. Rio de Janeiro, n. 19, p. 135170, 2007.

Uma face contemporânea da barbárie. In: SOUZA, G. (Org.). O Social em Perspectiva: políticas, trabalho, serviço social.
EDUFAL, p. 12-45, 2013.

NETTO, J. P.; BRAZ, M. Economia política: uma introdução crítica. São Paulo: Cortez, 2010.

. Uma face contemporânea da barbárie. In: SOUZA, G. (Org.). O Social em Perspectiva: políticas, trabalho, serviço social. EDUFAL, p. 12-45, 2013.

PEREIRA, P. Política Social: temas \& questões. São Paulo: Cortez, 2011.

ROSANVALLON, P. A nova questão social: repensando o Estado Providência. Brasília: Instituto Teotônio Vilela, 1998.

SAES, D. Cidadania e capitalismo: uma crítica à concepção liberal de cidadania. 2003. Disponível em: <http://professor.pucgoias.e du.br/SiteDocente/admin/arquivosUpload/ 14467/material/cidadania\%20e\%20a\%20cri tica\%20liberal.pdf>. Acesso em: 26 jan. 2017.

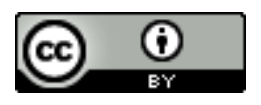

License information: This is an openaccess article distributed under the terms of the Creative Commons Attribution License, which permits unrestricted use, distribution, and reproduction in any medium, provided the original work is properly cited.

Artigo recebido em 10 de julho de 2017.

Avaliado em 21 de novembro de 2017.

Aceito em 04 de dezembro de 2017.

Publicado em 19 de dezembro de 2017.

Como citar este artigo (ABNT):

FELIPPE, Jonis Manhães Sales. O Estado Social e os fundamentos históricos e conceituais da política social: origem e institucionalização. Estação Científica (UNIFAP), Macapá, v. 7, n. 3, p. 37-49, set./dez. 2017. 